\title{
Follow up in embolic stroke of undetermined source: new clinical treatment algorithm including long-term cardiac monitoring and PFO closure in a prospective open-label observational study
}

Johanna Heinrich $\mathrm{MD}^{1 *}$, Katharina Feil $\mathrm{MD}^{1,2 *}$, Clemens Küpper $\mathrm{MD}^{1}$, Frank A. Wollenweber $\mathrm{MD}^{1,4}$, Moritz Sinner MD , Stefan Kääb MD ${ }^{3}$, Lars Kellert $\mathrm{MD}^{1,5}$

1 Department of Neurology, Ludwig-Maximilians University, Munich, Germany

2 German Center for Vertigo and Balance Disorders, Ludwig-Maximilians University, Munich, Germany

3 Department of Medicine 1, Ludwig-Maximilians University, Munich, Germany

4 Institute for Stroke and Dementia Research, Ludwig-Maximilians University, Munich, Germany

5 Department of Neurology, University of Heidelberg, Heidelberg, Germany

*These authors contributed equally

Objective: Recent trials of patent foramen ovale (PFO) closure to prevent recurrent stroke found overall stroke reduction in the PFO closure group compared with antiplatelet therapy alone. However several aspects in the management of patients with embolic stroke of undetermined source (ESUS) and PFO remain unclear.

Methods: An interdisciplinary cardio-neurological treatment algorithm was developed to standardize the management of patients with ESUS (see figure). All patients were aimed to receive long-term cardiac monitoring (e.g. implantable cardiac monitor, ICM). Depending on the age (cut off $\geq 60$ years) and the transesophageal detection of a relevant PFO there was an assignment to different treatment regimens including antiplatelet therapy, oral anticoagulation (OAC) and PFO-closure. Follow-up period will be at least 36 months. The study was approved be local authorities and patients gave informed consent.

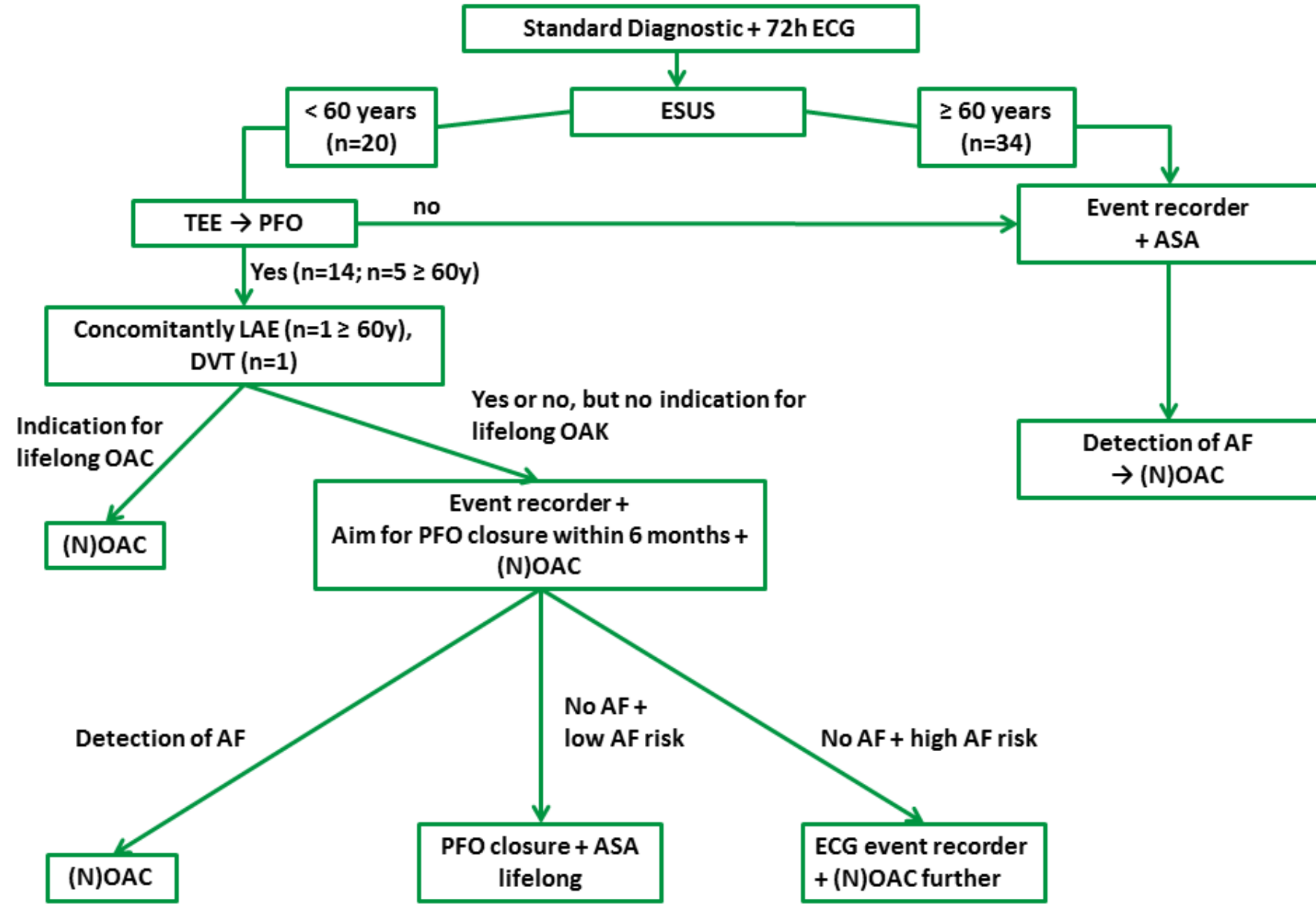

Results: The algorithm has been implemented in January 1, 2018. Since then, 54 patients (age 66y, 34y-87y) have been included. Mean CHA $2 S_{2} V_{A S C}$ score was 5 (2-8). A PFO was detected in 14 patients. An event recorder was implanted in 31 patients, for different reasons, e.g. due to patient wishes, this was not done in the other cases. As secondary stroke prevention 42 patients received antiplatelet therapy and 12 OAC.

\begin{tabular}{cccccccccc}
\hline Patients & Male & Age & $\begin{array}{c}\mathrm{CHA}_{2} \mathrm{DS}_{2} \mathrm{~V} \\
\text { ASC score }\end{array}$ & $\begin{array}{c}\text { NIHSS } \\
\text { (admission) }\end{array}$ & DVT & ICM & PFO & (N)OAC Antiplatelet \\
\hline 54 & 32 & $66(34-87)$ & $5(2-8)$ & 4 & 1 & 31 & 14 & 12 & 42 \\
\hline
\end{tabular}

The following table shows the number of patients who fulfil the individual CHA2DS2VASC score risk factors:

\begin{tabular}{ccccccccc}
\hline & CHF & Hypertension & $\begin{array}{c}\text { Diabetes } \\
\text { mellitus }\end{array}$ & Stroke/TIA & $\begin{array}{c}\text { Vascular } \\
\text { disease }\end{array}$ & $\begin{array}{c}\text { Age } \\
\mathbf{6 5 - 7 4}\end{array}$ & $\begin{array}{c}\text { Age } \\
>\mathbf{7 4}\end{array}$ & Female \\
\hline Patients & 3 & 45 & 13 & 54 & 8 & 13 & 16 & 22 \\
\hline
\end{tabular}

Conclusions: Due to this new treatment algorithm $57 \%$ of stroke patients with ESUS received an ICM. In about $1 / 4$ of patients a PFO was detected and closure is aimed within 6 months after stroke depending on detection of AF and risk stratification for AF. Overall, this open-label prospective observational study will help to resolve various unanswered questions regarding the treatment regimen of ESUS patients with and without PFO. The results will have implications for future management of patients with ESUS and might help identifying patients best suited for PFO closure.

Corresponding authors:

Johanna Heinrich, MD; Department of Neurology; E-mail: Johanna.heinrich@med.uni-muenchen.de; Phone ++4989440075819;

Dr. Katharina Feil, MD; Department of Neurology and German Center for Vertigo and Balance Disorders; E-mail: katharina.feil@med.uni-muenchen.de; Phone ++498970953678

Ludwig-Maximilians University; Marchioninistrasse 15; 81377 Munich, Germany 